\title{
A Technological and Typological Analysis of Lithic Material from Skovmosen I, Denmark
}

\author{
Thomas Eggers-Kaas ${ }^{1,2,6}$, Jesper Borre Pedersen ${ }^{1}$, Christian Steven Hoggard ${ }^{1,5}$, Florian Sauer ${ }^{1,3}$, \\ Jan Hilgart ${ }^{4}$ and Felix Riede ${ }^{1}$

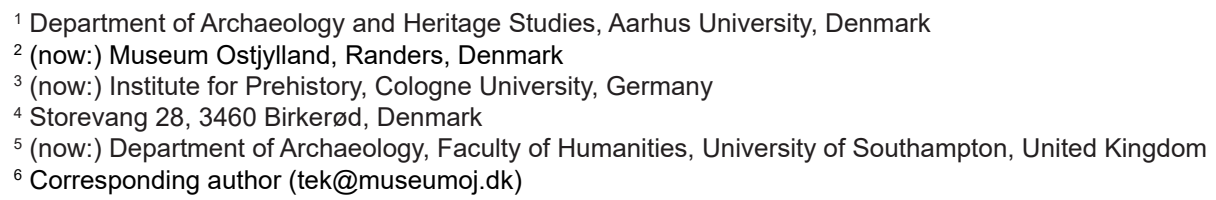

\begin{abstract}
During road construction work, material attributed to the Final Palaeolithic was discovered at Skovmosen I, near Kongens Lyngby on Zealand, eastern Denmark. Although it is regularly mentioned in reviews of the southern Scandinavian Final Palaeolithic, the Skovmosen I assemblage has hitherto remained poorly described. We here review the site's discovery history and its context. Aided by a three-dimensional digital recording protocol, this article details the assemblage composition and its technology. The assemblage is comprised of tanged points, scrapers and burins, alongside blades and cores as primary reduction products. Although evidently disturbed by the road construction that led to the site's discovery, the material likely reflects the remains of a small Final Palaeolithic locale, where diverse activities were carried out.
\end{abstract}

\author{
ARTICLE HISTORY \\ Received 28 Ja- \\ nuary 2019; \\ Accepted 27 No- \\ vember 2019
}

\section{KEYWORDS}

Final palaeolithic; Late glacial; Lithic technology; Tanged points; 3D recording.

\section{Introduction}

Late Glacial finds in Denmark are, when compared to other periods, relatively rare (https://slks.dk/fileadmin/user_upload/kulturarv/publikationer/emneopdelt/arkaeologi/aud/reg-kronologi.pdf), with a small number of contexts representing, following traditional cultural assignment, the Hamburgian (c. 12500-12000 cal BC), Federmesser (c. 12000$10800 \mathrm{cal} \mathrm{BC})$, Bromme (c. $11500-10500 \mathrm{cal} \mathrm{BC})$ and Ahrensburgian (c. 11000-10000 cal BC) cultures. Perhaps one of the most frequently found typological and taxonomic entities throughout this period is the Bromme culture, representing the majority of entries in the Fund \& Fortidsminder (Sites and Monuments Record), provided by the Danish Agency for Cultures and Palaces (Riede 2017a).

The status of these cultures, the transitions between and the causes underlying the attendant material culture changes observable in the archaeological record are currently much debated (Buch Pedersen 2014; Riede 2013; 2014; Riede \& Pedersen 2018; Sauer \& Riede 2018; Weber et al. 2011). The difficulties of disentangling these patterns and processes of culture change are, in part grounded in the scarci- ty of well-described sites. Of the Late Glacial entries in the Danish Sites and Monuments Record (Fund \& Fortidsminder), the majority of find spots actually represent stray-finds of either projectile points or knapping debris; larger and well-described assemblages are rare (Riede 2017b:27-31). This register is used primarily for administrative purposes, however, and changes in registration practice over time and between the many registrants are difficult to account for. Nonetheless, the database still offers the most immediate overview of the archaeological finds from present-day Denmark.

In a recent review of the Danish Final Palaeolithic, the site of Skovmosen I on Zealand in eastern Denmark has been listed among those assemblages (Brinch Petersen 2009), yet the material has only very briefly been described previously and never before in English (Boye 2006; Hilgart 2003). We here offer an in-depth description of legacy materials associated with the Skovmosen assemblage.

In a collaboration initiated by the site's discoverer Jan Hilgart, this paper details a selection of artefacts recovered from the Final Palaeolithic locale, Skovmosen I, in eastern Denmark. We present an overview of the locale and couple this with a tech- 


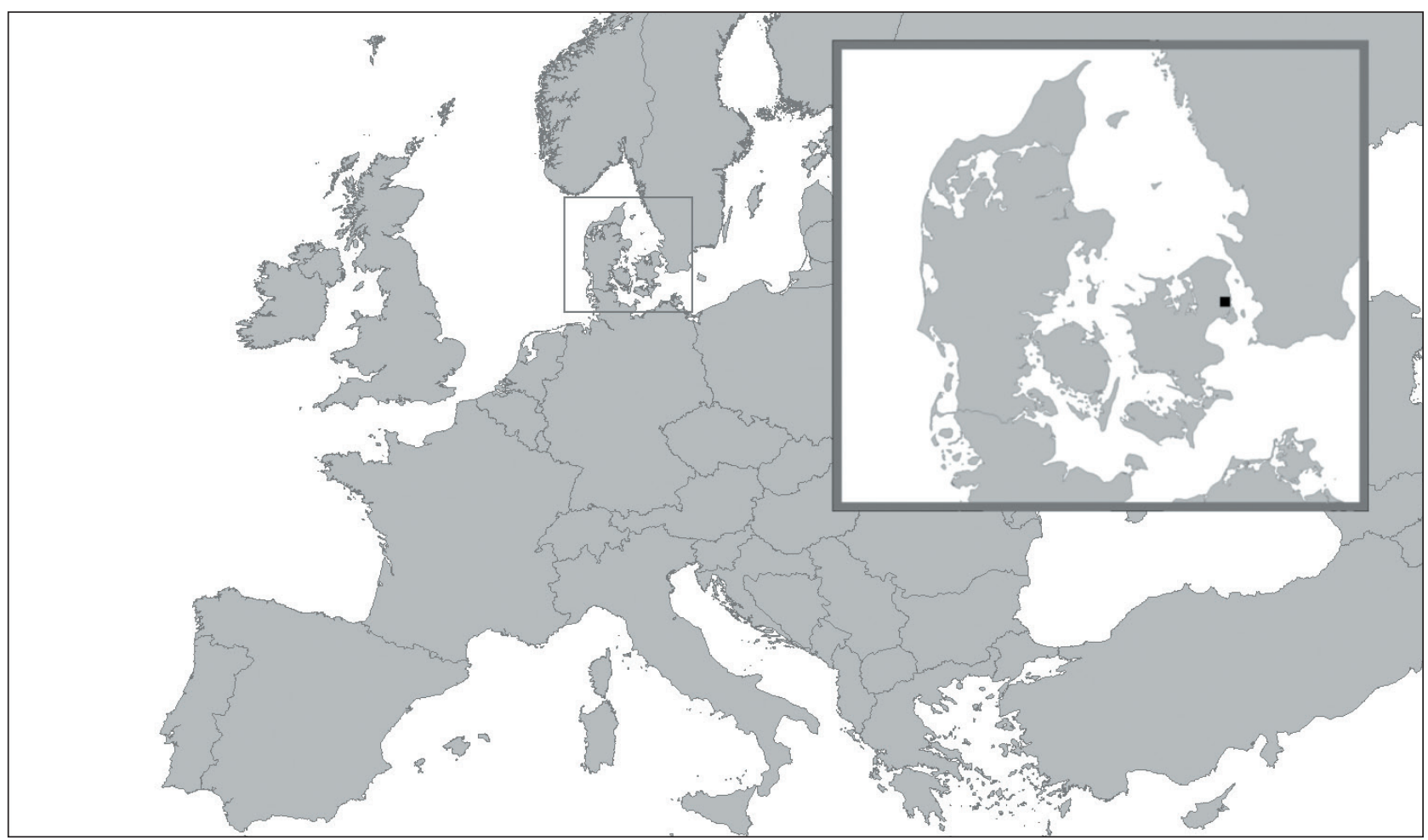

Figure 1. The location of Skovmosen I in northern Zealand, Denmark.

nological analysis of the assemblage, including observations made at the time of discovery and initial retrieval. Furthermore, in the promotion of accessibility (Marwick 2017), we present digital models of selected artefacts, and finally attempt to place Skovmosen I in a wider context of the Final Palaeolithic in the region.

\section{Skovmosen}

Skovmosen I (Sted \& lok. nr. 020307-178) is located in the present municipality of Lyngby-Taarbæk, Zealand, in eastern Denmark, situated between Kongens Lyngby and Jægersborg north of Copenhagen (Figure 1). Following an expansion of the Helsingør motorway in 1995, one of the authors (Jan Hilgart) discovered several Final Palaeolithic flint artefacts along the edge of a tunnel valley close to the remains of the present-day bog of Skovmosen. Skovmosen, literally meaning 'the forest bog', is situated at the bottom of a small hill and on the northern shore of the bog (Figure 2). The site is situated on the eastern side of the motorway, approximately 300 meters northwest of the late $19^{\text {th }}$ century historical monument of Garderhøjfortet.
As part of the motorway construction, a small drainage canal, which would lead surface water away from the road, was dug to the adjacent bog. It was at the construction site and among the spoil heaps from this drainage that the lithic artefacts were retrieved. As the site seemed heavily disturbed by the construction, permission was given, through a collaboration with Københavns Amtsmuseumsråd, to sieve the spoil heaps and retrieve any additional artefacts. This salvage operation at the site was stalwartly continued and the spoil heaps were systematically sieved through the winter of 1995/1996. In total, 240 artefacts were recovered.

Today, the area of Skovmosen falls under the jurisdiction of Kroppedal Museum and the assemblage is currently on display at Friboeshvile Manor in Lyngby. Although the site is briefly mentioned by Hilgart (2003), Boye (2006) and Brinch Petersen (2009), we here provide a first detailed account and description of the material in English, with particular focus on the blades, tools and cores.

\section{Locational context and discovery}

As no excavation was carried out due to the site's disturbed condition, no definite location or extent 
Figure 2. Photograph of Skovmosen I, taken by J. Hilgart.

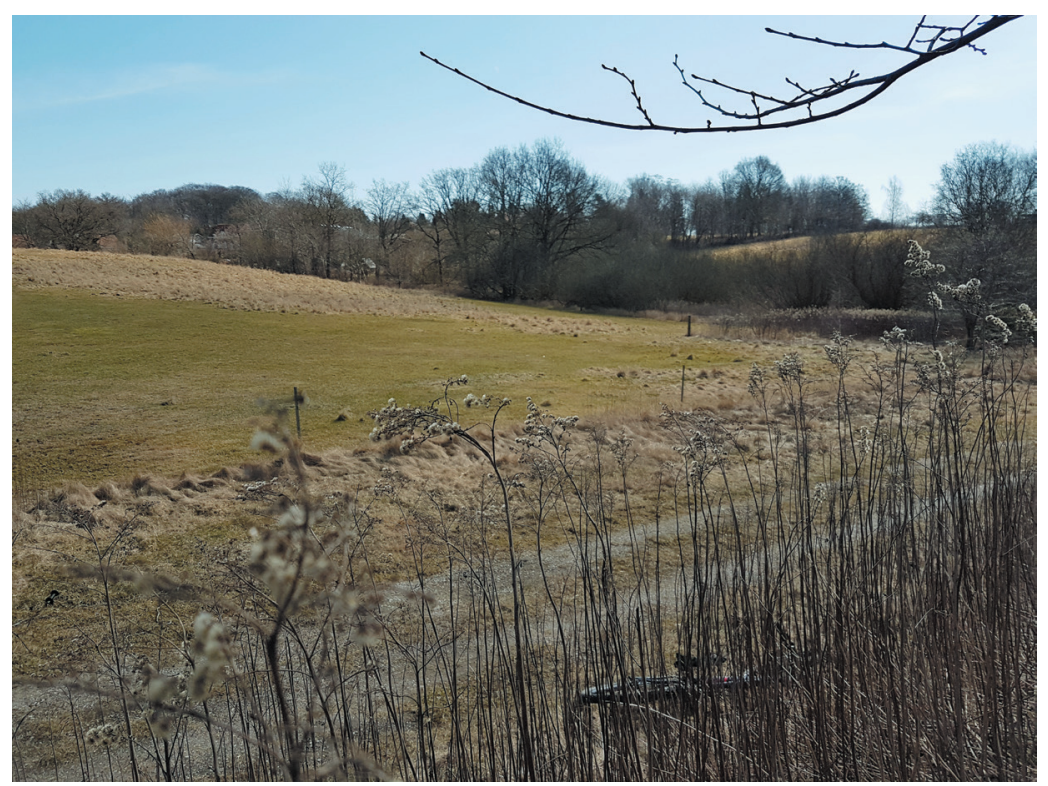

can be established. From observations made by Hilgart during the discovery and his subsequently made map, it can be surmised that at least one, and possibly two, concentrations are represented in the material, which were situated in peaty soil with a sandy subsoil. Both concentrations were most likely located near the shoreline of the bog/palaeolake, adjacent to the motorway. The lithic material was distributed across an area measuring approximately $240-250 \mathrm{~m}^{2}$ in total. Observations made at the time of discovery suggest, that the drainage canal had intersected a single scatter of lithic material, representing - potentially - a coherent site. By the same token, it is important to note that one of the artefacts recovered around the spoil heaps was a Late Mesolithic transverse arrowhead. Some mixing - especially at the locales eastern end - had evidently occurred, although whether this mixing relates to multiple occupations or the very process that led to the discovery of the assemblage - or some combination of these factors - remains entirely speculative. Prehistoric occupation at the site well after the Final Palaeolithic is certainly implicated and must be taken into account when considering the assemblage.

\section{Lithic analysis}

Of the 240 artefacts recorded, we selected five for 3D documentation by means of Structure from Motion (SfM): one complete tanged point (x2), one incomplete tanged point $(\mathrm{x} 1)$, one scraper (x29) and two cores (x48 and x51). A copy of the fully interactive models can be retrieved from our Open Science Framework (OSF) project page: https://osf.io/jeuxf/.

Although photogrammetry has been a compelling approach, not only within archaeology but others disciplines within recent years (Baier \& Rando 2016; De Reu et al. 2013; Green et al. 2014; Grün et al. 2004; López et al. 2016; Westoby et al. 2012), the methodology has not gained momentum when it comes to presenting lithic assemblages. In particular with regard to archaeological lithics, drawing curiously persists as the preferred standard mode of representation, despite the evident differences in stylistic approaches (Saville 2009) and the fact that, in most other sciences, drawing is restricted to idealised representations rather than actual specimens (Lopes 2009). In contrast to drawing, SfM constructs a 3D model based on regular overlapping 2D photographs of a given artefact, capturing the object's shape and from. It does so by identifying pixel-by-pixel spatial information in each photograph needed for triangulation, and by then using corresponding points on different overlapping photographs, to render a model in a dimensionally stable Euclidean space.

We used a portable photogrammetry rig to record the artefacts, adapted from the setup reported by Porter et al. (2016). For the necessary level of detail, a 50MP Canon EOS 5DS with a $50 \mathrm{~mm}$ macro lens was used to obtain the overlapping photographs, following the detailed workflow presented in Appendix 1. Note that, evidently, a refinement of these latter protocols is still necessary. Even when 


\begin{tabular}{|ccc|}
\hline Category & Sub-category & Count $(\boldsymbol{\Sigma}=\mathbf{2 4 0})$ \\
\hline Secondary reduction production & Tanged point (complete) & 1 \\
& Tanged point (broken) & 4 \\
& Transverse arrowhead & 22 \\
& Scraper & 8 \\
Primary reduction production & Burin & 1 \\
& Combination tool & 17 \\
& Blade (complete) & 2 \\
\hline Debitage & Blade (broken) & 5 \\
\hline
\end{tabular}

Table 1. Breakdown of artefacts from Skovmosen I.

substantial efforts are made to standardise recording procedures, the results of individual capture events vary. To facilitate offline reading, lithic illustrations therefore also accompany this article. In recording the technological attributes of the assemblage, the "Dynamical Technological Classification of Scandinavia Lithic Blade Industries", made accessible by

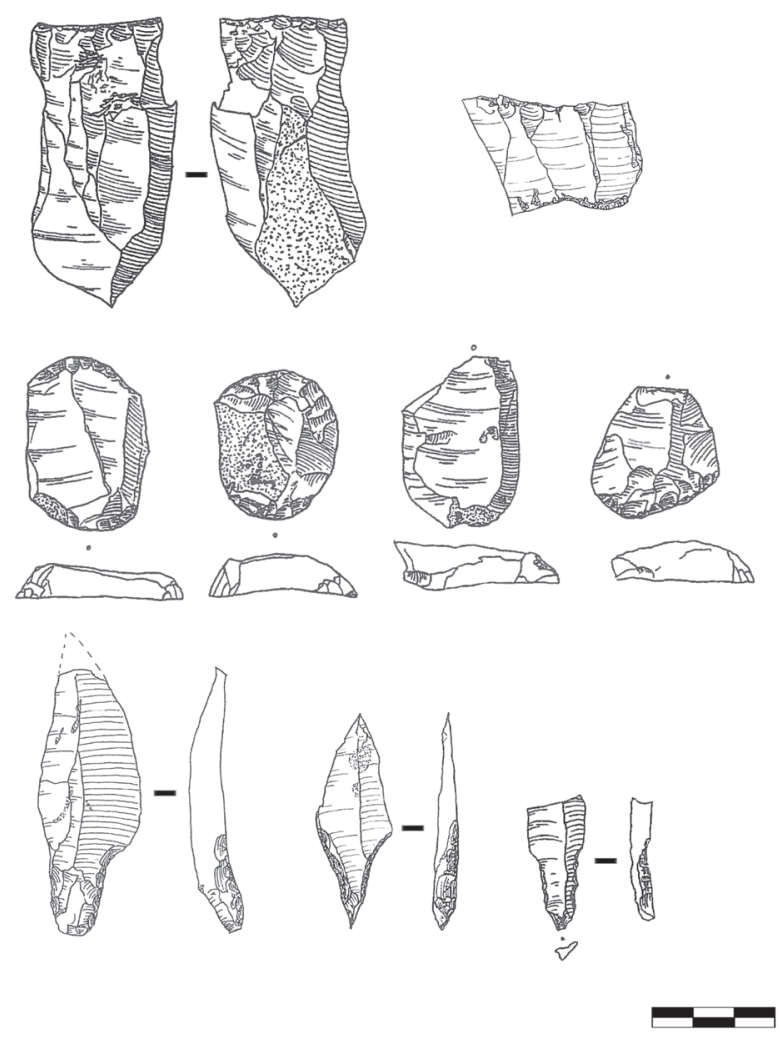

Figure 3.Top row, from left to right: cores (x48, x51). Middle row, from left to right: a selection of scrapers (x29, x28, $x 43, x 46)$. Bottom row, from left to right: a selection of tanged points $(x 1, x 2, x 3)$. Illustrations by J. Hilgart. the Nordic Blade Technology Network (Sørensen 2013) was adopted.

\section{Typological and technological analysis}

The Skovmosen I lithic material is characteristic of an assemblage recovered through surface reconnaissance. The assemblage consists of material at all stages of production, with primary material (cores, unretouched blades and debitage) and secondary products (burins, scrapers and tanged points) present (Table 1); smaller debitage, however, is lacking. An illustration of a selection of artefacts can be seen in Figure 3.

\section{Raw material}

The lithic material is covered by red to olive coloured patina rendering an exact classification of the raw material used in the assemblage difficult. On pieces which are only partly covered by patina, the material appears to be Cretaceous (Senonian) flint.

\section{Primary reduction products}

Blades

In total, 17 complete blades were identified, as well as a further four fragments. Of the latter, two can be refitted into one complete blade (x18) and are therefore treated as such in this analysis. The blades vary 

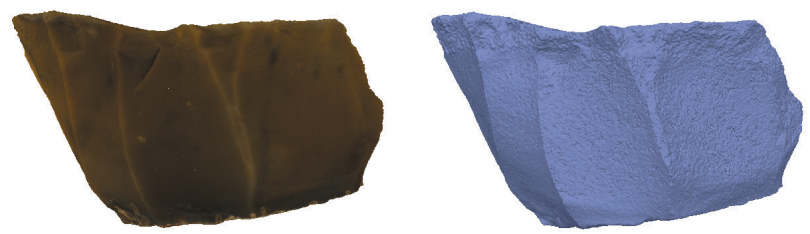

Figure 4. From left to right; textured 3D model and mesh view of $x 51$.

from regular $(\mathrm{n}=12)$ to widely-irregular $(\mathrm{n}=6)$ examples, with a large number of blades showing signs of preparation of the core prior to the production of the blade $(\mathrm{n}=12)$. A considerable number of blades, where observable, also indicate the use of direct hard knapping technique, with large and thick butts, and pronounced bulb formation $(n=6)$. Experimental analyses have shown, however, that unambiguous discrimination between direct soft and hard hammer percussion is difficult (Damlien 2015; Darmak \& Apel 2008), with important implication for the validity of traditional inferences of hammer types from bulb morphology (e.g. Hartz 1987).

\section{Cores}

In total, 12 cores were identified throughout the assemblage. These relatively small pieces range in height from $22 \mathrm{~mm}$ to $69 \mathrm{~mm}$, with an average of $41.9 \mathrm{~mm}$. The majority of cores are conical in morphology $(\mathrm{n}=10)$, and feature a single striking platform $(n=11)$. Only one core $(x 62)$ exhibits two striking platforms. A single-front or circular exploitation method is typically represented, with cortex localised and positioned on the 'back' of the core.

Five cores can be categorised as blade cores, four of which feature a relatively high core flatness, oriented towards blade and bladelet production (Figure 4). All five blade cores feature a single smooth platform and a conical morphology, and demonstrate successful blade and bladelet production, with very few examples of stepped or hinged negative distal-end scars on their circumference. One core $(\mathrm{x} 48)$ is the exception to this rule, with multiple hinged and stepped negative distal-end scars, layered around the core's circumference (Figure 5). This example is also of greater size (15 mm longer than all other blade cores), exhibits a greater number of blade and bladelet removals, and is the only example to feature platform grinding and abrasion. Despite of the presence of many cores, no

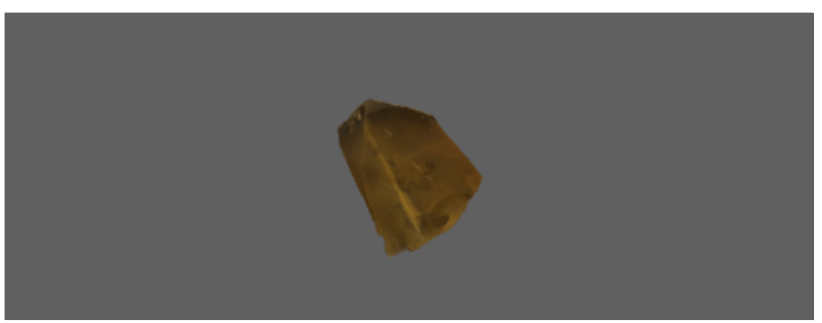

Figure 4a. 3D rendered model of $x 51$.

hammerstones were recovered from the site. However, deep negative scars on the majority of cores, following the above frameworks, allude to their use.

\section{Tools}

\section{Burins}

The burins $(\mathrm{n}=8)$ are all dihedral burins on an edge, made on thick blades most likely produced by
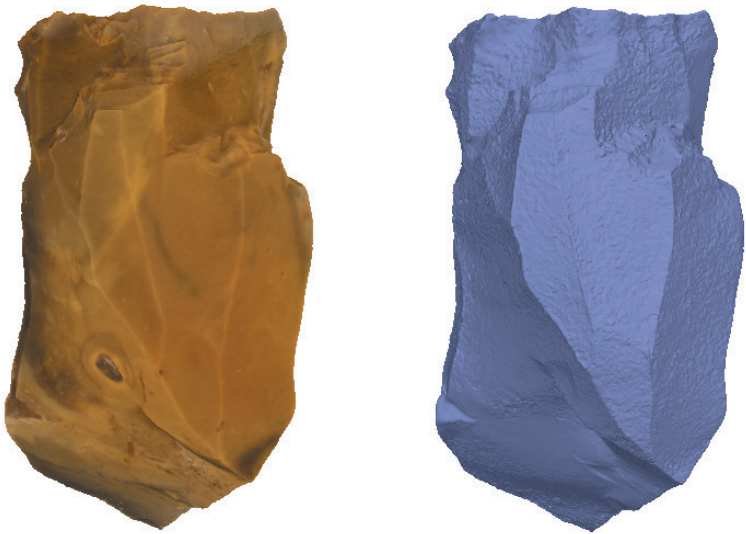

Figure 5. From left to right; textured 3D model and mesh view of $x 48$.

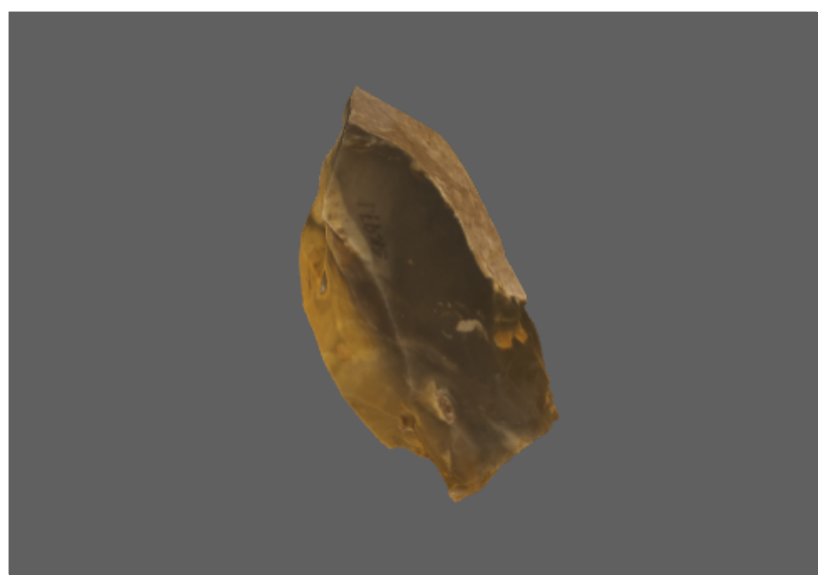

Figure 5a. 3D rendered model of $x 48$. 

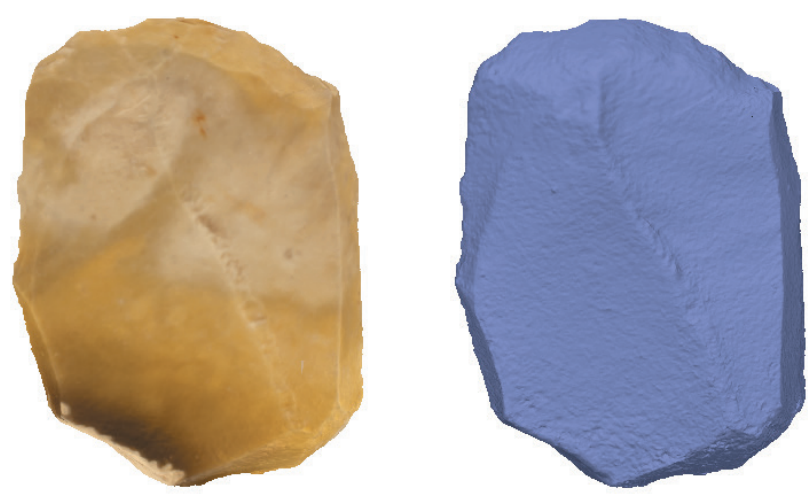

Figure 6. From left to right; textured 3D model and mesh view of $x 29$.

hard-hammer percussion. One is significant in having a retouched tang in the proximal end, and may be the resulting modification or re-tooling on a fractured tanged artefact, such as a projectile point. Another can be described as a combination tool with a
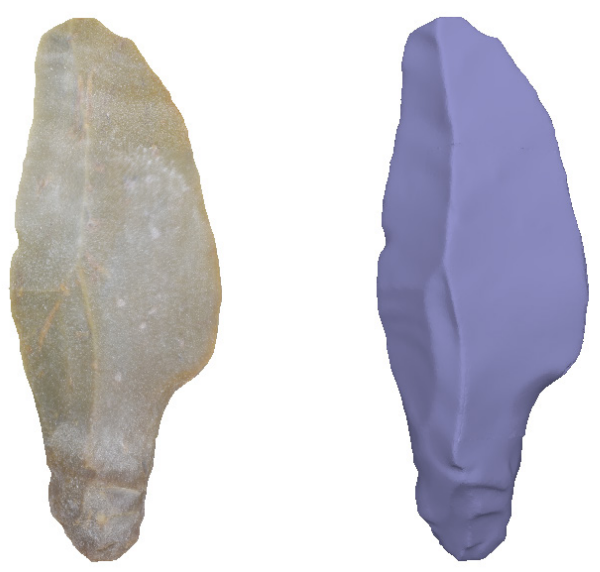

Figure 7. From left to right; textured $3 \mathrm{D}$ model and mesh view of $x 1$.

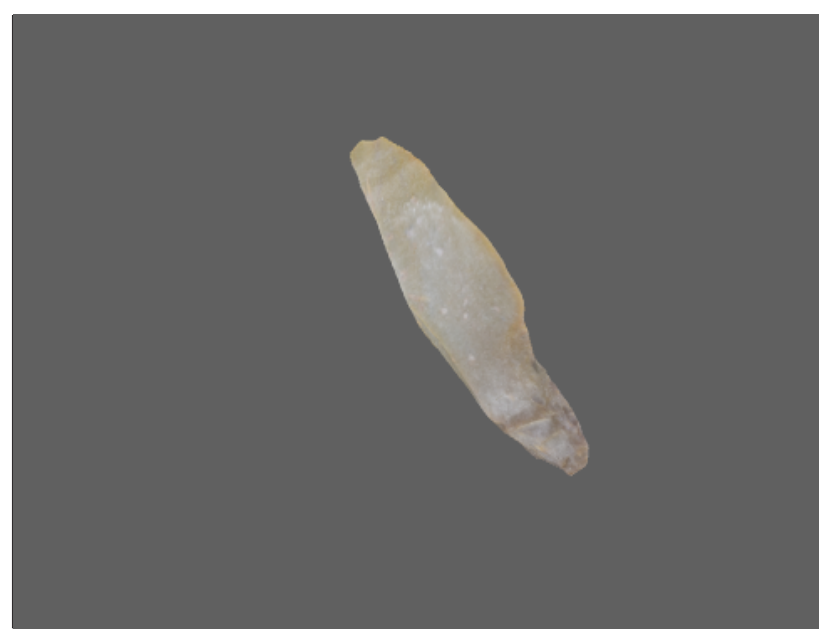

Figure $7 \mathrm{a} .3 \mathrm{D}$ rendered model of $\mathrm{x} 1$.

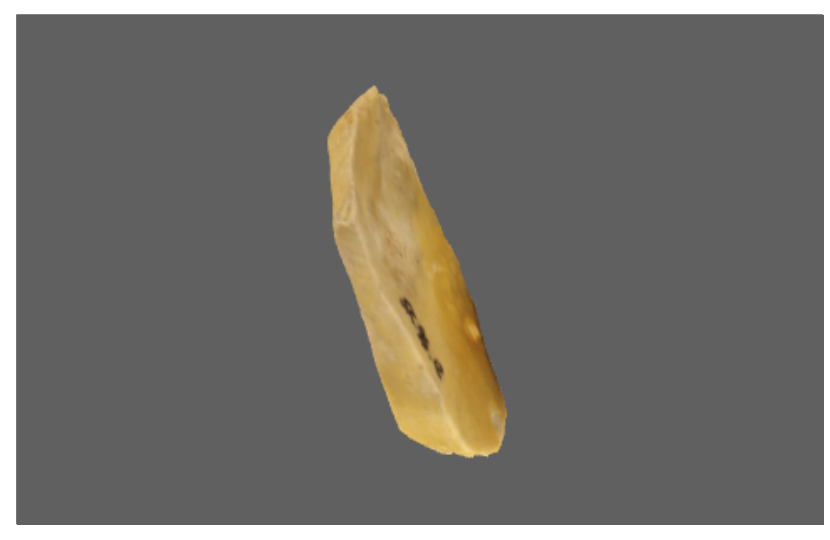

Figure 6a. 3D rendered model of $x 29$.

dihedral burin on an edge in one end and concave retouch on the other end.

\section{Scrapers}

Scrapers make up the largest part of the tool assemblage $(n=22)$. These primarily consist of scrapers made on flakes $(n=14)$ where the bulk are made into smaller and almost circular 'thumbnail' scrapers $(\mathrm{n}=12)$. Scrapers on blades are represented as well $(\mathrm{n}=8)$. Only one scraper preserves an intact bulb and butt indicating a direct hard percussion technique, fully in line with the evidence from primary production.

\section{Tanged points}

Finally, the assemblage contains five large tanged points, one complete and four fractured. Artefact x 1 is a slightly fractured tanged point, with minor damage at the distal end (Figure 7). This is, however, a clean unpatinated break and represents a post-depositional breakage. It is therefore here regarded as a whole artefact. This example is made from a thick regular blade, with two dorsal ridges and an evenly distributed curvature. It measures $66 \mathrm{~mm}$ in length, $25 \mathrm{~mm}$ in width, $8 \mathrm{~mm}$ in thickness and weighs $13.2 \mathrm{~g}$. The tang is located at the proximal part where the rather thick and unfaceted platform and pronounced bulb are still intact. The tanged retouch is featured on both sides of the tang and is knapped from the ventral side of the blade. The blade features converging edges towards the distal end.

Artefact $\mathrm{x} 2$ is a complete projectile point measuring $53 \mathrm{~mm}$ in length, $18 \mathrm{~mm}$ in width, $6 \mathrm{~mm}$ in thickness and weighing $3.4 \mathrm{~g}$ (Figure 8). Technologically similar to $\mathrm{x} 1$, this point is made from a regular 
blade, with two dorsal ridges and a tang located at the proximal end. The tang-forming retouch is applied on both sides, from the ventral side of the blade as on $\mathrm{x} 1$, but here removing the platform and bulb. The distal portion of the projectile has been made to converge with small scalar retouch. The weight and dimensions of these more or less complete points aligns them well with ethnographically documented dart-heads (Riede 2009).

Artefacts $\mathrm{x} 3, \mathrm{x} 4$ and $\mathrm{x} 5$ are all projectile point fragments and specifically, tang fragments. The presence of such fragments, together with primary production of blades, may provide insights into some of the activities at the site. The fracturing of these projectile points could have been the result of impact damage from hunting (Fischer et al 1984). It may also indicate re-tooling of the damaged projectile points upon return from the hunt. Similar to $\mathrm{x} 2, \mathrm{x} 3$ is made from a regular, rather slender, blade with two dorsal ridges and retouch on both sides at the proximal end, from the ventral side of the blade, and the bulb removed. Artefact $\mathrm{x} 4$ is also made from a regular, slender blade with two dorsal ridges with retouch on both sides, at the proximal end from the ventral side of the blade. Contrary to $\mathrm{x} 2$ and $\mathrm{x} 3$, the bulb and striking platform are here intact. Artefact $\times 5$ is also made from a regular, slender blade with two dorsal ridges and retouched on both sides at the proximal end from the ventral side of the blade. Both the bulb and striking platform on $\mathrm{x} 5$ are intact.

\section{Debitage}

A total of 173 debitage pieces were collected, of which $57 \%$ demonstrate signs of hard percussion technique, $15 \%$ attest to the likely use of a softer hammer or indirect percussion and a further $28 \%$ could not be determined. $61 \%$ of the debitage retain some cortex, underlining that primary lithic reduction might have been taking place at the site.

\section{The place of the Skovmosen assemblage in the Danish Final Palaeolithic}

Located on slightly higher ground near a body of freshwater, the Skovmosen site shows a locational
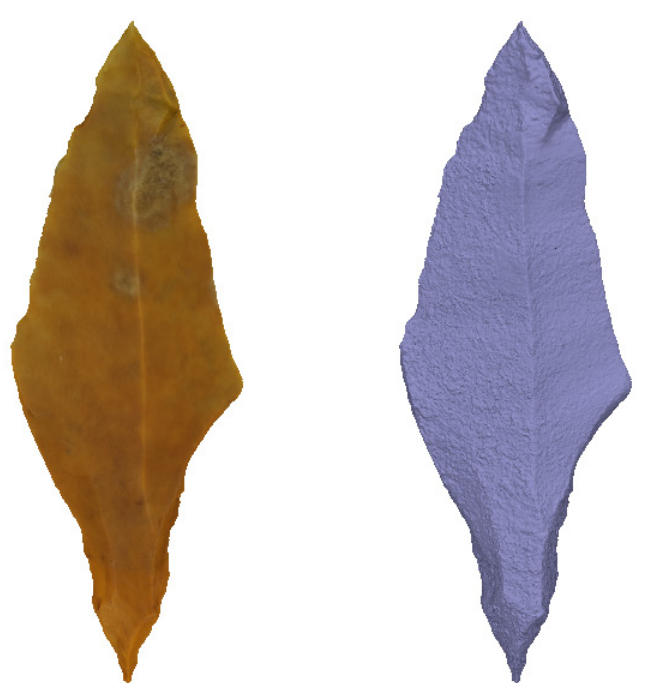

Figure 8. From left to right; textured 3D model and mesh view of $x 2$.

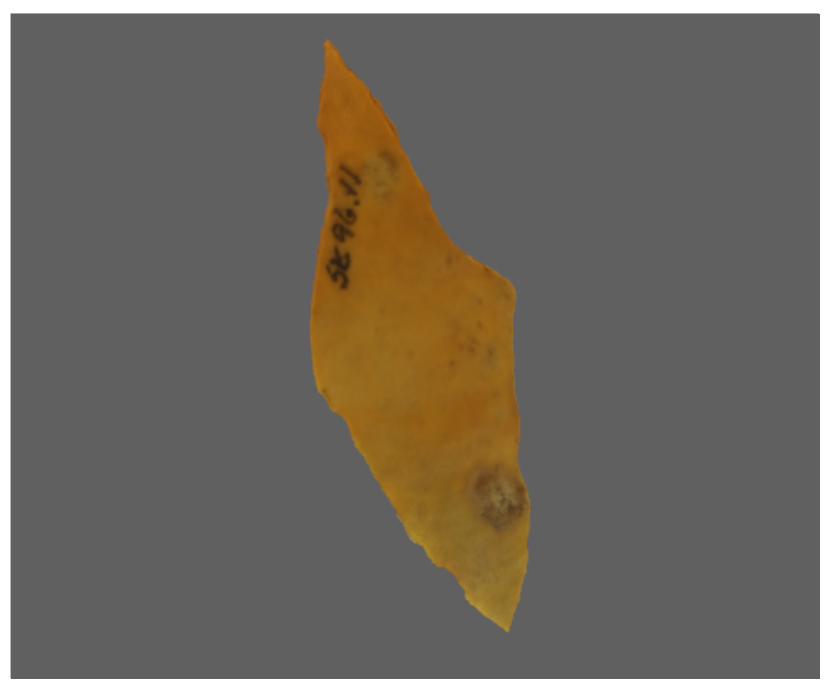

Figure 8 a. 3D rendered model of $x 2$.

position common for the southern Scandinavian Late Glacial. In this, Skovmosen is comparable to larger sites such as Trollegave, Stoksbjerg Vest and Bro, which also are located near lakes (Johansen 2003; Pedersen 2009:120). Such a location could, following Fisher (1991), Donahue and Fisher (2015) and Petersen and Johansen (1994), indicate the status of a more permanent site as opposed to temporary hunting stations. A breakdown of the tools from Skovmosen I shows a distribution of scrapers (63\%), burins ( $23 \%)$ and complete as well as broken tanged points (14\%). This spectrum of tools, together with the evidence of primary on-site lithic production would also support the notion that we are dealing with a habitation site. As the lithic technology primarily reflects direct hard per- 
cussion technique, it is difficult to assign the material to any one cultural complex or to distinguish Final Palaeolithic from later knapping products within the assemblage. Hard hammer percussion occurs in the Federmesser culture (Hartz 1987), the Bromme culture (Madsen 1983) as well as in the early Preboreal Maglemosian culture (Sørensen 2006).

Turning to the cultural historical placement of the Skovmosen I assemblage, the technological and typological traits presented above would traditionally place Skovmosen I within the Bromme culture. Ever since the discovery of a large tanged point in lacustrine deposits in the cliffs at Nørre Lyngby in Vendsyssel, north-western Denmark (Jessen \& Nordmann 1915) and the later excavation of the locus classicus of Bromme in eastern Denmark (Mathiassen 1946), the Bromme culture has been enshrined as an autochthonous southern Scandinavian Final Palaeolithic culture - represented first and foremost by the presence of large tanged points. The diagnostic power of this artefact class has been questioned, however (Kobusiewicz 2009b), and a series of critical voices have expressed doubts as to the validity of the Bromme culture as an actual culture-historical phenomenon on par with similarly labelled 'cultures' elsewhere (Kobusiewicz 2009a; 2009b; Riede 2013; 2014; 2017a; Sauer \& Riede 2018) thereby making even disturbed sites such as Skovmosen I important in order to elucidate such a priori cultural groups as the Bromme culture. Put simply, the issue can be reduced to the diagnostic capacity and specificity of the types and technologies associated with the Bromme culture. Large tanged points occur in the Final Palaeolithic of Europe already well before the postulated emergence of the Bromme culture (Riede et al. 2011) independently of whether one follows the available long or short chronologies (cf, Riede and Edinborough 2012; Fischer et al. 2013).

Spatially, the occurrence of large tanged points appears to correspond with the northern range expansion of the broader Final Magdalenian/Federmessergruppen complex and their occurrence in greater numbers northwards stands out as a trend rather than a discrete distribution of separate types marking separate ranges or territories (cf. Bokelmann 1978). The presence of large tanged points in Final Magdalenian/Federmessergruppen contexts prior to the suggested date range of the Bromme culture precludes the interpretation of their occurrence outside of its presumed 'core area' as cultural contact or expansion. Instead, an interpretation of these sites as more or less specialised exploitation sites - related perhaps to the hunting of large mammals such as elk and giant deer with particularly heavy armatures (Tomka 2013) in the landscapes of late Allerød eastern Denmark where these animals may have been particularly abundant (Mortensen et al. 2014) - may be more parsimonious as earlier suggested by Bokelmann (1978). These considerations lead us to be cautious with regard to a placement of the Skovmosen I assemblage into the Bromme culture, as previously suggested by Hilgart (2003), Boye (2006) and Brinch Petersen (2009). At any rate, the Skovmosen assemblage is comprised only of surface finds retrieved semi-systematically from an already heavily disturbed context. Neither lithic technology nor artefact typology can unambiguously resolve the degree of admixture or the cultural affiliation of the assemblage. All of this severely compromises our ability to arrive at robust inferences regarding site function and chronology as the mixed nature of the assemblage, also hints at some later Mesolithic interference.

\section{Concluding remarks}

The Late Glacial in southern Scandinavia has been the subject of much renewed research effort lately. Brinch Petersen (2009) has provided a useful review that, however, has plainly demonstrated that (i) true habitation sites of appreciable size are rare when compared to regions further to the south and that (ii) many of the known assemblages remain incompletely published. We have here attempted to address the latter shortcoming by presenting and discussing the small Final Palaeolithic assemblage from Skovmosen I. Despite obvious signs of admixture with later material, it is not unlikely that the assemblage can, by and large, be placed into the Final Palaeolithic. We are more cautious, however, about further assigning the material to any of the traditionally recognised Final Palaeolithic 'cultures', given recent debates about their validity and the retrieval history as well as the likely incom- 
pleteness of the Skovmosen I assemblage. Given the general rarity of Pleistocene archaeology in southern Scandinavia coupled with the fact that many Final Palaeolithic locales have discovery and retrieval histories not unlike Skovmosen I but are similarly mentioned in regional or inter-regional syntheses (e.g. Groß et al. 2016), we argue that our description makes a useful cautionary contribution to the present corpus of sites and assemblages.

\section{Acknowledgements}

TEK, JBP, CSH, FS and FR are supported by Independent Research Fund Denmark grant \#610700059B. We thank Jan Hilgart for the initiative and opportunity to investigate the Skovmosen I assemblage. Maria Lisette Jacobsen, Kroppedal Museum, is thanked for providing additional archive information.

\section{Bibliography}

Baier, W. and Rando, C., 2016. Developing the use of Structure-from-Motion in mass grave documentation. Forensic Science International, 261, 19-25. https://doi.org/10.1016/j.forsciint.2015.12.008

Bokelmann, K., 1978. Ein Federmesserfundplatz bei Schalkholz, Kreis Dithmarschen. Offa, 35, 36-54.

Boye, L.D., 2006. Gentofte Kommune, in Københavns Amt. Kulturhistorisk Oversigt. Oldtiden Indtil 1050. København: Københavns Amt \& Kroppedal Museum, 221-34.

Brinch Petersen, E., 2009. 'The Human Settlement of Southern Scandinavia 12 500-8 700 cal BC'. In: M. Street, N. Barton and T. Terberger, eds. Humans, Environment and Chronology of the Late Glacial of the North European Plain. Mainz: Verlag des Römisch-Germanischen Zentralmuseums, 89-129.

Buch Pedersen, K., 2009. Stederne Og Menneskene. Istidsjegerne Omkring Knudshoved Odde. Vordingborg: Museerne.dk.

Buch Pedersen, K., 2014. Brommeproblemet 2.0 - kommentar til Riedes artikel 'Brommeproblemet'. Arkeologisk Forum, 30, 7-11.

Damlien, H., 2015. Striking a difference? The effect of knapping techniques on blade attributes. Journal of Archaeological Science, 63, 122-35. https://doi.org/10.1016/j.jas.2015.08.020

Darmak, K. and J. Apel, 2008. 'The Dogma of Immaculate Perception. An experimental study of bifacial arrowheads and a contribution to the discussion on the relationship between personal experience and formalised analysis in experimental archaeology'. In: M. Sørensen and P. Desrosiers, eds. Technology in Archaeology - Proceedings of the SILA Workshop: The Study of Technology as a Method for Gaining Insight into Social and Cultural Aspects of Prehistory, the National Museum of Denmark, Copenhagen, November 2-4, 2005. Copenhagen: The National Museum, 173-86.

Donahue, R. and Fisher, A., 2015. A Late Glacial family at Trollesgave, Denmark. Journal of Archaeological Science, 54, 313-324. https://doi.org/10.1016/j.jas.2014.12.018

De Reu, J., Plets, G., Verhoeven, G., De Smedt, P., Bats, M., Cherretté, B., De Maeyer, W., Deconynck, J., Herremans, D., Laloo, P., Van Meirvenne, M. and De Clercq, W., 2013. Towards a three-dimensional cost-effective registration of the archaeological heritage. Journal of Archaeological Science, 40 (2), 1108 21. https://doi.org/10.1016/j.jas.2012.08.040 
Fischer, A., Hansen, P.V. and Rasmussen, P., 1984. Macro and Micro Wear Traces on Lithic Projectile Points. Journal of Danish Archaeology, 3, 19-46. https://doi.org/10.1080/0108464X.1984.10589910

Fischer, A., Mortensen, M.F., Henriksen, P.S., Mathiassen, D.R. and Olsen, J., 2013. Dating the Trollesgave site and the Bromme culture - chronological fix-points for the Lateglacial settlement of Southern Scandinavia. Journal of Archaeological Science, 40 (12), 4663-74. https://doi.org/10.1016/j.jas.2013.06.026

Green, S., Bevan, A. and Shapland, M., 2014. A comparative assessment of structure from motion methods for archaeological research. Journal of Archaeological Science, 46 (1), 173-81.

https://doi.org/10.1016/j.jas.2014.02.030

Groß, D., Berckhan, S., Hauschild, N., Räder, A. and Sohst, A., 2016. 'Pinnberg 7 - Technologische Untersuchungen zur Überprüfung der internen Chronologie’. In: K. Gerken, D. Groß S. and Hesse, eds. Neue Forschungen zum Mesolithikum. Beiträge zur Jahrestagung der Arbeitsgemeinschaft Mesolithikum in Rotenburg (Wümme), 19.-22. März 2015, Archäologische Berichte des Landkreises Rotenburg (Wümme), Band 20. Oldenburg: Isensee Verlag, 5-24.

Grün, A., Remondino, F. and Zhang, L.I., 2004. Photogrammetric Reconstruction of the Great Buddha of Bamiyan, Afghanistan. Photogrammetric Record, 19 (107), 177-99.

https://doi.org/10.1111/j.0031-868X.2004.00278.x

Hartz, S., 1987. Neue spätpaläolithische Fundplätze bei Ahrenshöft, Kreis Nordfriesland. Offa ,44, 5-52.

Hilgart, J., 2003. Brommefund i jordbunkerne på byggeplads. Aktuel Arkeologi 2, p. 17.

Jessen, A.H. and Nordmann, V.J.H., 1915. Ferskvandslagene Ved Nørre Lyngby. Copenhagen: C.A. Reitzel.

Johansen, A.D. 2003. Stoksbjerg Vest. Et senpaleolitisk fundkompleks ved Porsmose, Sydsjelland. Fra Brommetil Abrensburgkultur i Norden. København: Det Kongelige Nordiske Oldskriftselskab.

Kobusiewicz, M., 2009a. Whether the Bromme culture existed? Folia Praehistorica Posnaniensia, XV, 75-91.

Kobusiewicz, M., 2009b. 'The Lyngby point as a cultural marker'. In: M. Street, R.N.E. Barton and T. Terberger, eds. Humans, Environment and Chronology of the Late Glacial of the North European Plain. Mainz: Verlag des Römisch-Germanischen Zentralmuseums, 169-78.

Lopes, D.M., 2009. Drawing in a Social Science: Lithic Illustration. Perspectives on Science, 17 (1), 5-25. https://doi.org/10.1162/posc.2009.17.1.5

López, J.A.B., Jiménez, G.A., Romero, M.S., García, E.A., Martín, S.F., Medina, A.L. and Guerrero, J.A.E., 2016. 3D modelling in archaeology: The application of Structure from Motion methods to the study of the megalithic necropolis of Panoria (Granada, Spain). Journal of Archaeological Science, Reports 10, 495506. https://doi.org/10.1016/j.jasrep.2016.11.022

Madsen, B. 1983. New Evidence of Late Palaeolithic Settlement in East Jutland. Journal of Danish Archaeology, 2, 12-34. https://doi.org/10.1080/0108464X.1983.10589889

Marwick, B., 2017. Computational Reproducibility in Archaeological Research: Basic Principles and a Case 
Study of Their Implementation. Journal of Archaeological Method and Theory, 24 (2), 424-50. https://doi.org/10.1007/s10816-015-9272-9

Mathiassen, T., 1946. En senglacial Boplads ved Bromme. Aarboger for nordisk Oldkyndighed og Historie, $121-70$.

Mortensen, M.F., Henriksen, P.S. and Bennike, O., 2014. Living on the good soil: Relationships between soils, vegetation and human settlement during the late Allerød period in Denmark. Vegetation History and Archaeobotany, 23 (3), 195-205. https://doi.org/10.1007/s00334-014-0433-7

Petersen, V.P. and Johansen, L., 1994. Rensdyrjægerne ved Sølbjerg på Lolland. Nationalmuseets Arbejdsmark, 80-97.

Porter, S.T., Roussel, M. and Soressi, M., 2016. A Simple Photogrammetry Rig for the Reliable Creation of 3D Artifact Models in the Field. Lithic Examples from the Early Upper Paleolithic Sequence of Les Cottés (France). Advances in Archaeological Practice, 4 (1), 71-86. https://doi.org/10.7183/2326-3768.4.1.71

Riede, F., 2009. The loss and re-introduction of bow-and-arrow technology: A case study from the southern Scandinavian late Paleolithic. Lithic Technology, 34, 27-45. https://doi.org/10.1080/01977261.2009.11721072

Riede, F., 2013. 'Brommeproblemmet' - senglacial kulturtaksonomi og dens forståelses- og forvaltningsmæssige implikationer. Arkaologisk Forum, 29, 8-14.

Riede, F., 2014. Brommeproblemet 2.1 - et gensvar til Kristoffer Buck Pedersens kommentar. Arkaologisk Forum, 31, 39-45.

Riede, F., 2017a. The 'Bromme Problem' - Notes on understanding the Federmessergruppen and Bromme culture occupation in southern Scandinavia during the Allerød and early younger Dryas chronozones. Arkeologiske studier, 12, 61-86.

Riede, F., 2017b. Splendid Isolation. The Eruption of the Laacher See Volcano and the Southern Scandinavian Late Glacial Hunter-Gatherers. Aarhus: Aarhus University Press.

Riede, F. and Edinborough, K., 2012. Bayesian radiocarbon models for the cultural transition during the Allerød in southern Scandinavia. Journal of Archaeological Science, 39, 744-456. https://doi.org/10.1016/j.jas.2011.11.008

Riede, F., Laursen, S.T. and Hertz, E., 2011. Federmesserkultur i Danmark. Belyst med udgangspunkt i en amatørarkæologs flintsamling. KUML, 9-38.

Riede, F. and Pedersen, J.B., 2018. Late Glacial Human Dispersals in Northern Europe and Disequilibrium Dynamics. Human Ecology, 46 (5), 621-632. https://doi.org/10.1007/s10745-017-9964-8

Sauer, F. and Riede, F., 2018. A Critical Reassessment of Cultural Taxonomies in the Central European Late Palaeolithic. Journal of Archaeological Method and Theory, 26 (1), 1-30.

https://doi.org/10.1007/s10816-018-9368-0 
Saville, A., 2009. 'The illustration of Mesolithic artefacts and its contribution to the understanding of Mesolithic technology'. In: S. McCartan, P.C. Woodman, R.J. Schulting and G. Warren, eds. Mesolithic Horizons. Papers Presented at the Seventh International Conference on the Mesolithic in Europe, Belfast 2005. Volume 2, Oxford: Oxbow, 745-53.

Sørensen, M. 2006. 'Teknologiske traditioner i Maglemosekulturen. En diakron analyse af Maglemosens flækkeindustri.' In: B. V. Eriksen, ed. Stenalderstudier. Tidlig mesolitiske jegere og samlere i Sydskandinavien. Højbjerg: Jysk Arkæologisk Selskab.

Sørensen, M., 2013. Dynamical technological Classification of Scandinavian Lithic Blade Industries. Unpublished manuscript.

Tomka, S.A., 2013. The Adoption of the Bow and Arrow: A Model Based on Experimental Performance Characteristics. American Antiquity, 78(3), 553-69. https://doi.org/10.7183/0002-7316.78.3.553

Weber, M.-J., Grimm, S.B. and Baales, M., 2011. Between warm and cold: Impact of the Younger Dryas on human behavior in Central Europe. Quaternary International, 242, 277-301.

https://doi.org/10.1016/j.quaint.2010.12.002

Westoby, M.J., Brasington, J., Glasser, N.F., Hambrey, M.J. and Reynolds, J.M., 2012. 'Structure-from-Motion' photogrammetry: A low-cost, effective tool for geoscience applications. Geomorphology, 179, 300314. https://doi.org/10.1016/j.geomorph.2012.08.021 


\section{Appendix 1}

\section{A Technological and Typological Analysis of Lithic Material from Skovmosen I, Denmark.}

Eggers-Kaas, T., Pedersen, J.B., Hoggard, C.S., Sauer, F.R. and Riede, F.

\section{Supplementary information}

\section{SfM Recording strategy}

These two workflows are designed to introduce the reader to the Structure from Motion (SfM) process, from the capturing of suitable images to the final creation of a 3D textured model. The first will detail the rig components, the setup and necessary stages, and best practice. The second workflow will consider the image-process (post-masking application). This process is a modified form of the workflow detailed by:

Thi Porter, S., Roussel, M. and Soressi, M. (2016). A Simple Photogrammetry Rig for the Reliable Creation of 3D Artifact Models in the Field. Lithic Examples from the Early Upper Palaeolithic Sequence of Les Cottes (France). Advances in Archaeological Practice , 4 (1): 71-86.

\section{Rig Components}

The following equipment and software is used throughout this SfM process:

- Black velvet (for the photo backdrop)

- Backdrop support e.g. foam tiles or boxes

- Turntable e.g. a kitchen turntable (used to rotate the object)

- Lighting (for object illumination)

- Kneadable rubber eraser (artefact support)

- Scale (see below)

- Camera tripod (camera support: prices vary, choose a sturdy tripod if possible)

- Camera (depending on the size and nature of the object)

- A carrying case (to support the draping of the velvet and for portability)

- Agisoft PhotoScan Processional Edition (photogrammetry software)

- Adobe Photoshop CC (for masking of the artefact background; can also be done in PhotoScan)

- Meshlab (3D Mesh Editing software)

- Optional: Laptop with camera software e.g. EOS Utility (for remote shooting)

\section{Rig Setup and Use}

1. Open the carrying case and drape the background fabric (black velvet) over the case.

2. Set down the turntable (with the scale and colour card glued on the turntable), with the $0^{\circ}$ mark facing forward. The scale and colour card can be found here: https://conservancy.umn.edu/bitstream/ handle/11299/172480/Photogrammetric_scale_noncoded_markers_plus.pdf ?sequence=28\&isAllowed $=y$.

3. Position the camera on the tripod at approximately the same height as the turntable. Connect the 
camera to the laptop and load up the EOS Utility software (if remote shooting).

4. Assemble the lighting; ensure light is aimed downwards towards the turntable's centre, and on both sides of the camera. Portable LED panel lamps can be used for greater portability, however they will have a limited lighting time and will require frequent charging.

5. Place the artefact rubber eraser on the centre of the turntable.

\section{Stage 1a: Photography Instructions (Remote Shooting)}

A suitable folder structure is first necessary as two batches of photographs will be taken. There will be one folder (named by the model ID) and five subsequent sub-folders:

- Folder(e.g. ID_2405_321)

o A_Side (the images taken for the first surface of the artefact)

o B_Side (the images taken for the second surface of the artefact)

o A_Mask (the masked images for the 1st surface - produced in Adobe Photoshop)

o B_Mask (the masked images for the 2nd surface - produced in Adobe Photoshop)

o Models (the .ply, obj files and textures produced by the process)

In EOS Utility ensure the directory is set to the location of the A_Side sub-folder. With the camera positioned at approximately the same height as the turntable, take the first picture. In line with the Archaeological Data Service (http://guides.archaeologydataservice.ac.uk/g2gp/Photogram_Toc) the following practices were adopted:

- The camera is always set to Manual, with fine-tuning of the focus performed in EOS Utility.

- The International Standards Organisation (ISO) i.e. the sensitivity of the camera's light sensor is set as low as possible, in order to minimise the amount of noise in each image.

- Low F-stops (apertures) were avoided as they tend to leave object parts out of focus with a shallow depth of field (the highest possible aperture was therefore used).

- A short shutter speed was generally required, given the low ISO, and high aperture.

- If photographs are taken manually, use a two-second delay in order to avoid blurriness that can result from movement caused by pressing the shutter button on the camera button.

Following the first picture rotate the turntable $30^{\circ}$ so that the $30^{\circ}$ mark is facing the camera. Take a second image. Continue rotating the turntable and taking photographs every $30^{\circ}$ until the turntable has been fully rotated (i.e., at the $60^{\circ}, 90^{\circ}, 120^{\circ}, 150^{\circ}, 180^{\circ}, 210^{\circ}, 240^{\circ}, 270^{\circ}, 300^{\circ}$, and $330^{\circ}$ marks). Using the tripod, raise the camera slightly and tilt it towards the target object. For small objects, we usually raise the camera approximately 5 to $10 \mathrm{~cm}$. Rotate the turntable so that the $10^{\circ}$ mark is facing the camera. Take a photo. Rotate the turntable $30^{\circ}$ so that the $40^{\circ}$ mark is facing the camera. Take another photo. Continue rotating the turntable and taking photographs every $30^{\circ}$ until the turntable has been fully rotated (i.e., at the $70^{\circ}$, $100^{\circ}, 130^{\circ}, 160^{\circ}, 190^{\circ}, 220^{\circ}, 250^{\circ}, 280^{\circ}, 310^{\circ}$, and $340^{\circ}$ marks). Raise the camera again and tilt it towards the target object. Rotate the turntable so that the $20^{\circ}$ mark is facing in the direction of the camera. Take a photo. Rotate the turntable $30^{\circ}$ so that the $50^{\circ}$ mark is facing the camera. Take another photo. Continue rotating the turntable and taking photographs every $30^{\circ}$ until the turntable has been fully rotated (i.e., at the $80^{\circ}, 110^{\circ}, 140^{\circ}, 170^{\circ}, 200^{\circ}, 230^{\circ}, 260^{\circ}, 290^{\circ}, 320^{\circ}$, and $350^{\circ}$ marks). At this point you should have taken 36 photographs. Depending on the shape of the object, it may be necessary to raise and tilt the camera once again and take an additional round of photographs in order to sufficiently capture the top of the object. Usually, we take fewer photographs at this camera position (e.g., four photos with the turntable at the $0^{\circ}$, $90^{\circ}, 180^{\circ}$, and $270^{\circ}$ positions.

Turn the object over, flipping it $\mathbf{1 8 0}^{\circ}$. What was previously the top of the object should now be facing downward towards the turntable's surface. Repeat the photography protocol as before, but in reverse. The directory should be now set to the 'B_Side'. In other words, begin taking photos with the camera in a very high position and work downward systematically rotating the object as before. 


\section{Stage 1b: Photography Instructions (Manual Shooting)}

For manual shooting, the above process is largely the same. The only exception is that images should be subsequent stored into a folder system following the capturing of $72+$ images. Ensure that the correct images are in the appropriate folders.

\section{Stage 2: Masking Procedure}

For the following image-processing workflow, and the generation of high-quality $3 \mathrm{D}$ models, the velvet background is 'masked' from the image. This means that Agisoft Photoscan Professional will ignore the background. This stage is essential to the Structure from Motion operation, as we are 'cheating' the camera and that the only structure it should consider is the artefact and turntable. This can be done in Agiosoft Photoscan Professional (see the next workflow), MS Paint, or automated through a batch process operation in Adobe Photoshop CC.

The masking script for this automated process is as follows:

1. Open a photo taken with the photogrammetry rig in Adobe Photoshop.

2. Open the action window by clicking on "Window" > "Action".

3. Create a new action by clicking on the square paper icon (circled in red in the screenshot below). Give the new action a name, and set it as a default action. Click "Record".

4. Using the "Magic Wand" tool a spot on the black background in the upper left hand corner of the image is performed. You will want to click on a place that will consistently select the background in each photo, you are processing and not the object. Make sure the box next to "Contiguous" is checked (as indicated by the white arrow). You may want to experiment with the tolerance level, but a setting of 15 usually works well.

5. This selection is then inverted through the "Select" > "Inverse" function.

6. If you zoom in, you will likely notice a line of black pixels is still included in your selection. To mitigate this, click "Select" > "Modify" > "Contract". Contract the selection by 2 or 3 pixels, depending on the resolution of your photos and the size of the remaining black area you observe.

7. Now you will create an alpha channel around representing your selection. To do this, click "Select" > "Save Selection". Save the selection as a new channel. Give the channel a name. Click "OK".

8. Next, save the photo by clicking "File" > "Save As". Save the image as a copy and a TIFF, and be sure to include the alpha channel. Click "Save".

9. You can use compression in order to avoid overly large file sizes. Click "OK" to save the file.

To run a batch process click "File" > "Automate" > "Batch". Select the script that is created, set your source folder as the folder containing the raw images, and choose the mask folder for your processed image. Make sure that "Override Action "Save As" Commands" is selected. Click "OK". Once the batch process has run, if you open the designated destination folder for your processed images, the image thumbnails should display with a white background.

\section{Stage 3: Importing photos (Agisoft Photoscan Professional)}

- The process will involve two 'chunks' (A side and B side), so in Agisoft Professional click on "Workspace” and select "Add chunk". Repeat twice. Chunks can be selected by double-clicking on the chunk description in the "Workspace" window.

- In each of these chunks import the masked-files (in .tif format) for each of these sides. The masking will have been done in Adobe Photoshop/Paint/CorelDraw. From here, the "import masks" should be clicked, ensuring that the mask is from the same file.

- Masks (in original or silhouette form) can be checked or altered in the "Photo" view. To alter a mask, 
click on an image, click the "Magic Wand" tool on the top toolbar and the area you also wish to mask. By clicking "ctrl" + "shift" + "A" on the mask you integrate the new area into the mask. Other selection tools can be used to select different regions or areas. The tolerance (strength of the masking) can also be changed by clicking “Options...” on the "Magic Wand” icon.

\section{Stage 4: Aligning photos (Agisoft Photoscan Professional)}

- This stage allows the computer to calculate where the camera positions are. These should be around the entirety of the image, in three bands (the three camera orientations).

- Cameras can be aligned for each side separately or together using the "Batch Process" function under the "Workflow" tab. In this new window click on "Add", choose "Align Photos" on the "Job Type" tab, and ensure that this is applied to "All Chunks". A high accuracy is favourable (time vs. quality), but ensure that "constrain features to mask" is selected. It is always good to ensure that the project is saved after each stage so select "Save project after each step", save as appropriate. Click "Ok" to run the process if the save function did not automatically run the process.

- Following this process, close the dialogue box and you should be able see the position of the cameras and the aligned photos (in point cloud form). To hide the trackball, in the centre of the screen, click the "Show Trackball" function under "Show/Hide items" in the "View" tab.

- Check that the camera positions are in the correct area and that the point cloud is not too busy.

- Note: the bounding box/region needs to encapsulate all you wish to model (including the scale). To do this use the region tools on the panel above the viewing window. Rotate, resize and position as necessary. Whatever is not in the bounding box will not be processed further.

- Stray points, close to the point cloud, may hinder the level of detail produced throughout later stages. These can be deleted through the "Free form selection" function, with the relevant areas highlighted and deleted (using the "Delete" button on the keyboard). Because these are scattered and do not cluster we can assume that these points are sources of error and not integral to the model.

\section{Stage 5: Building a dense cloud (Agisoft Photoscan Professional)}

- Using the "Batch Process..." function in "Workflow" again, remove the previous process and add "Build Dense Cloud" to the "Job Type". This stage will add further points now we are satisfied with the camera alignment. Set the "Quality" to however you see appropriate, and leave "Depth filtering" on "Aggressive". "Reuse depth maps" should also be selected to "No". Run this process. If you click on the "Dense cloud" option we can then view the model in greater detail. At present, this is a not a mesh but many points (if you zoom in you can see this).

\section{Stage 6: Chunk alignment, merging and mesh creation (Agisoft Photoscan Professi- onal)}

- This next stage involves taking the two dense clouds, aligning each perspective, and subsequently merging to produce one final model.

- The alignment stage can be done automatically, however, in some instances this may not work correctly and manual alignment may be necessary.

- For automatic alignment, merging and mesh creation:

o Choose "Workflow" on the header, and choose "Align Chunks...". We keep the "Method" as "Point based", as we are using the dense cloud, the "Accuracy" as we see appropriate and "Point 
Limit" to the default number. Again, we tick the "Constrain features to mask" function, so we can ignore the background.

o Upon completion, we can click "Show Aligned Chunks" on the icons above the viewing window, and see how the software has aligned the point clouds. Click off this when done.

o We can now edit these point clouds to align and consider just the dense cloud and the scale we wish to keep. In one chunk, using the rectangular tool we can delete the scale and putty, as previous. Continue to clean the image, removing noise where possible. In the second chunk, we want to keep some part of the scale, so we can scale appropriately later. Therefore, remove half of the scale board and the putty. Again, tidy as appropriate. When we again click "Show Aligned Chunks", we can now see the aligned artefact with one scale bar.

o If the quality of the model is better on one part of the shape than on another chunk then the low-quality section of that particular chunk can be deleted, using the same stages as above.

o The chunks are still two separate entities and we now need to merge the chunks. To do that we go to "Workflow" and "Merge Chunks". Here we combine the models (ignoring the markers), and click "Ok". If we now click on the "Merged Chunk" we can now see one chunk with all references points in one model. Resize and reposition the bounding box as appropriate.

o We can now build a mesh, using the "Build Mesh" function in the "Workflow" tab. Leave the "Surface Type" as "Arbitrary", "Source Data" as the "Dense cloud" and increase the polygon count as necessary. Always aim high (c. 500,000), it is always easy to simplify later (you can not add further detail later!). Leave all other options as the default and click "OK”. This step is usually quite quick.

o At the top, above the viewing window, we now have more options and can click the "Mesh" icon and see the final product. Now we can add the texture (see below).

- For manual point alignment, and subsequent merging and mesh creation:

o Using markers we can align the two models. Using the "Batch Process" function, select the "Build Mesh" and "Build Texture", we want a texture so we can accurately pinpoint areas of topographical correspondence (ensure that the polygon count is high!). For the texture mapping we want the "Blending mode" as "Average", with a "Texture size" of 4096 and a "Texture count" of 1 . Colour correction does not work particularly well, so leave this unticked. These processes can also be applied to the above mesh now. When these two stages have been added click "OK”. Each chunk will now have a mesh and a texture.

o We now need to add corresponding markers on each chunk, ready for alignment. When you have decided on places for the markers (roughly 8-10 will work well), right-click on the areas and choose "Create Marker". Make sure that the markers are spaced out around the object (the further apart the better), on both sides, and that the ordering is consistent. Tip: take a screenshot of one chunk to better align the markers on another model.

o When the points have been placed on each chunk, go to "Align Chunks" and, this time, change the method to "Marker Based". Ignore the "Fix Scale" function as we have not yet made a scale.

o After clicking "Show Aligned Chunks", we can do the same operations as before, deleting noise in the dense cloud, the putty and scale bar on one image, and half of the scale bar and putty in another. Merge chunks as previous. We can then rebuild the mesh for this new model following the previous method.

\section{Stage 7: Solving the "putty issue" (Agisoft Photoscan Professional)}

- If we were to build a texture using the two models, the software will include photographs of the putty, and two discoloured areas will appear: one on the top of the artefact and one on the bottom of the artefact. 
- To fix this issue we will mask the putty in the photographs using the previous method of masking (by using the free-form selection or the rectangular selection tools). We however have many photographs, and not all are necessary to make a texture, so, using the "Disable cameras" function on half of the photographs and mask the others.

- If we run the "Build Texture" function now the issue should be fixed.

\section{Stage 8: Creating the scale (Agisoft Photoscan Professional)}

- There are two ways a scale can be created. Both use markers, the same markers used in the manual alignment. These are placed on the model or from the photographs.

o From the model:

$>$ Using the "Shaded" view of the model, place two markers (of a determinable length) on the model by right-clicking on a position and selecting "Create Marker". Repeat for a second point.

> Using the selection tools highlight both markers and select "Create Scale Bar". In the "Ground Control" window (this may need to be selected from the "View" function at the top of the program) we can now see "scale 1".

$>$ If we click on the scale, we can input the correct length underneath the "Distance (m)" header.

$>$ To ensure that your model is the correct size we click "Update" at the top of the panel.

o From the photographs:

$>$ Highlight a photograph (ideally a photograph from a pretty high angle) and add additional two markers on the scale, the program should auto-select the points for the other photographs and repeat the process as above.

o Note: If we do both methods, we can calculate the total error (as viewed in the left window).

\section{Stage 9: Exporting the model (Agisoft Photoscan Professional)}

- File/Export Model and choose whichever format you require (.obj and .ply are the most common model formats).

- In the options we can choose how we want the texture to be exporting (.jpg is fine).

- Click "Ok" and the model should be created. We can now open this up in MeshLab or any other program for additional tidying or modifications e.g. mesh-simplification. 